Supporting Information

for

\title{
Modification of Cellulose Nanocrystals with Quaternary Ammonium-Containing Hyperbranched Polyethylene Ionomers by Ionic Assembly
}

\author{
Lingqi Huang, ${ }^{1}$ Zhibin Ye, ${ }^{1, *}$ and Richard Berry ${ }^{2}$ \\ 1. School of Engineering, Laurentian University, Sudbury, Ontario P3E 2C6, Canada \\ 2. CelluForce Inc, Montreal, Quebec H3A 1K2, Canada \\ * Corresponding authors; email: zye@laurentian.ca (ZY)
}

Table of Content (Total 9 pages, 1 table, and 7 figures)

Table S1. Synthesis and characterization of the quaternary ammonium-containing hyperbranched polyethylene ionomers (I1-I6).

Figure S1. $\quad{ }^{1} \mathrm{H}$ NMR spectra of the quaternary ammonium-containing hyperbranched polyethylene ionomers (I1-I6) and a nonionic hyperbranched ethylene homopolymer.

Figure S2. AFM phase images of (a) original unmodified CNCs; (b) mCNC2; (c) mCNC3-3; (d) $\mathrm{mCNC} 4$; (e) and (f) mCNC6.

Figure S3. AFM height and phase images of aggregated $\mathrm{CNC}$ obtained in the control experiment by dropping CNC into pure THF (height images: $a$ and b; phase images: $a$ ' and b'), CTAB-CNC dispersed in THF (height images: c and d; phase images: c' and d').

Figure S4. Rheological data from small amplitude dynamic oscillation measurements (at 10 ${ }^{\circ} \mathrm{C}$ ) of organo-gels of mCNC3-3, mCNC4, and mCNC6 in THF at the same concentration of 75 mg mL $\mathrm{mL}^{-1}$ : (a) $\mathrm{G}^{\prime}$ and $\mathrm{G}^{\prime \prime}$ vs. $\omega$ at the strain of $100 \%$; (b) $\mathrm{G}^{\prime}$ and $\mathrm{G}^{\prime \prime}$ vs. $\omega$ at the strain of $0.01 \%$; (c) $\eta^{*}$ vs. $\omega$ at both strains of $100 \%$ and $0.01 \%$; (d) phase angle $(\delta)$ vs. $\omega$ at both strains.

Figure S5. Viscosity vs. shear rate curves of organo-gels of $\mathrm{mCNC} 3-3, \mathrm{mCNC} 4$, and mCNC6 in THF at $75 \mathrm{mg} \mathrm{mL}^{-1}$ obtained through steady shear measurements at $10{ }^{\circ} \mathrm{C}$.

Figure S6. TGA curves of the various EOC composites and neat EOC. The measurements were undertaken at $10^{\circ} \mathrm{C} / \mathrm{min}$ in $\mathrm{N}_{2}$.

Figure S7. DSC crystallization curves of neat EOC and various EOC composites collected at cooling rate of $10^{\circ} \mathrm{C} / \mathrm{min}$. 
Table S1. Synthesis and characterization of the quaternary ammonium-containing hyperbranched polyethylene ionomers (I1-I6). ${ }^{a}$

\begin{tabular}{|c|c|c|c|c|c|c|c|c|c|c|c|}
\hline \multirow[b]{2}{*}{ Ionomer } & \multirow{2}{*}{$\begin{array}{c}\text { Catalyst } \\
\text { (mmol) }\end{array}$} & \multirow{2}{*}{$\begin{array}{l}\text { Comonomer } \\
(\mathrm{mol} / \mathrm{L})\end{array}$} & \multirow{2}{*}{$\begin{array}{l}\text { Yield } \\
(\mathrm{g})\end{array}$} & \multirow{2}{*}{$\begin{array}{l}\mathrm{C}_{2} \mathrm{H}_{4} \\
\mathrm{TOF}^{c} \\
(1 / \mathrm{h})\end{array}$} & \multirow{2}{*}{$\begin{array}{c}\text { Comonomer } \\
\text { content }^{d} \\
(\mathrm{~mol} \%)\end{array}$} & \multirow{2}{*}{$\begin{array}{c}\text { Branch } \\
\text { density }^{e} \\
(1 / 1000 \mathrm{C})\end{array}$} & \multicolumn{5}{|c|}{ GPC results of hydrolyzed samples ${ }^{f}$} \\
\hline & & & & & & & $\begin{array}{c}\mathrm{M}_{\mathrm{w}} \\
(\mathrm{kg} / \mathrm{mol})\end{array}$ & PDI & $\begin{array}{c}{[\eta]_{\mathrm{W}}} \\
(\mathrm{mL} / \mathrm{g})\end{array}$ & $\begin{array}{c}\mathrm{K} \\
(\mathrm{mL} / \mathrm{g})\end{array}$ & $\alpha$ \\
\hline I1 & 0.1 & 0.10 & 1.20 & 17.9 & 0.2 & 92 & 18 & 1.7 & 9.5 & 0.55 & 0.30 \\
\hline $\mathrm{I} 2$ & 0.3 & 0.14 & 2.85 & 14.1 & 0.4 & 92 & 16 & 1.4 & 10.2 & 0.31 & 0.37 \\
\hline $\mathrm{I} 3$ & 0.1 & 0.20 & 1.40 & 20.8 & 0.7 & 85 & 18 & 1.3 & 10.2 & 0.20 & 0.41 \\
\hline I4 & 0.3 & 0.36 & 1.85 & 9.2 & 1.1 & 90 & 29 & 1.5 & 11.5 & 0.29 & 0.36 \\
\hline I5 & 0.1 & 0.50 & 0.82 & 12.2 & 1.5 & 88 & 15 & 1.3 & 10.1 & 0.17 & 0.43 \\
\hline I6 & 0.1 & 1.00 & 0.19 & 2.8 & 2.3 & 92 & 9 & 1.4 & 8.4 & 0.26 & 0.39 \\
\hline
\end{tabular}

$\bar{a}$ Polymerizations were all conducted under 1 atm ethylene pressure in $10 \mathrm{~mL}$ acetone as solvent at room temperature for $24 \mathrm{~h} .{ }^{b}$ Feed concentration of ionic liquid comonomer, AETMA ${ }^{+} \mathrm{BF}_{4}-{ }^{c}$ Ethylene turnover frequency (TOF) calculated as $\frac{\frac{m_{\text {yield }}(g)}{24(h) \times 28\left(\frac{g}{m o l}\right)}}{n_{\text {catalyst }(\text { mol })}} \cdot{ }^{d}$ Content of quaternary ammonium ion in ionomers, determined with ${ }^{1} \mathrm{H}$ NMR spectroscopy as $100 \% \times 4 I_{1} / 9 I_{2}$, where $\mathrm{I}_{1}$ represents the integration area for methyl protons on the ammonium ion $(c a .3 .25 \mathrm{ppm})$ and $\mathrm{I}_{2}$ represents peak integration area for protons on ethylene sequences (0.7-1.5 ppm). ${ }^{e}$ Branch density determined with ${ }^{1} \mathrm{H}$ NMR as $1000 \times 2 I_{3} / 3 I_{2}$, where $\mathrm{I}_{3}$ represents the integration area for methyl protons in ethylene sequences $(0.7-1.0 \mathrm{ppm}) .{ }^{f}$ Weight-average molecular weight $\left(\mathrm{M}_{\mathrm{w}}\right)$ and polydispersity index (PDI) were determined with the light scattering detector in the characterization of hydrolyzed ionomers with triple-detection GPC; weightaverage intrinsic viscosity $\left([\eta]_{\mathrm{w}}\right)$, Mark-Houwink-Sakurada parameters $(\mathrm{K}, \alpha)$ were measured with the viscosity detector in triple detection GPC. 

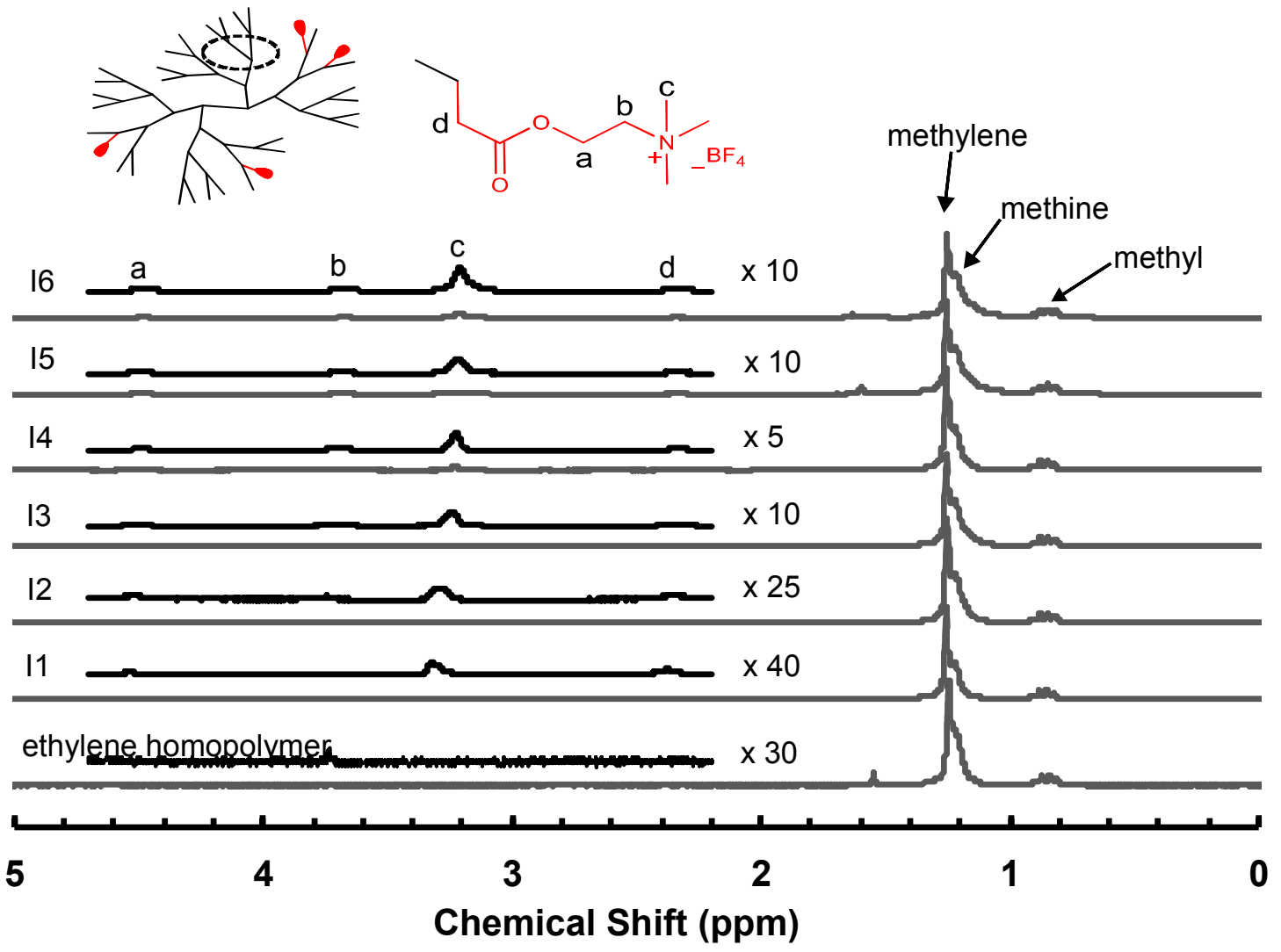

Figure S1. ${ }^{1} \mathrm{H}$ NMR spectra of the quaternary ammonium-containing hyperbranched polyethylene ionomers (I1-I6) and a nonionic hyperbranched ethylene homopolymer. 

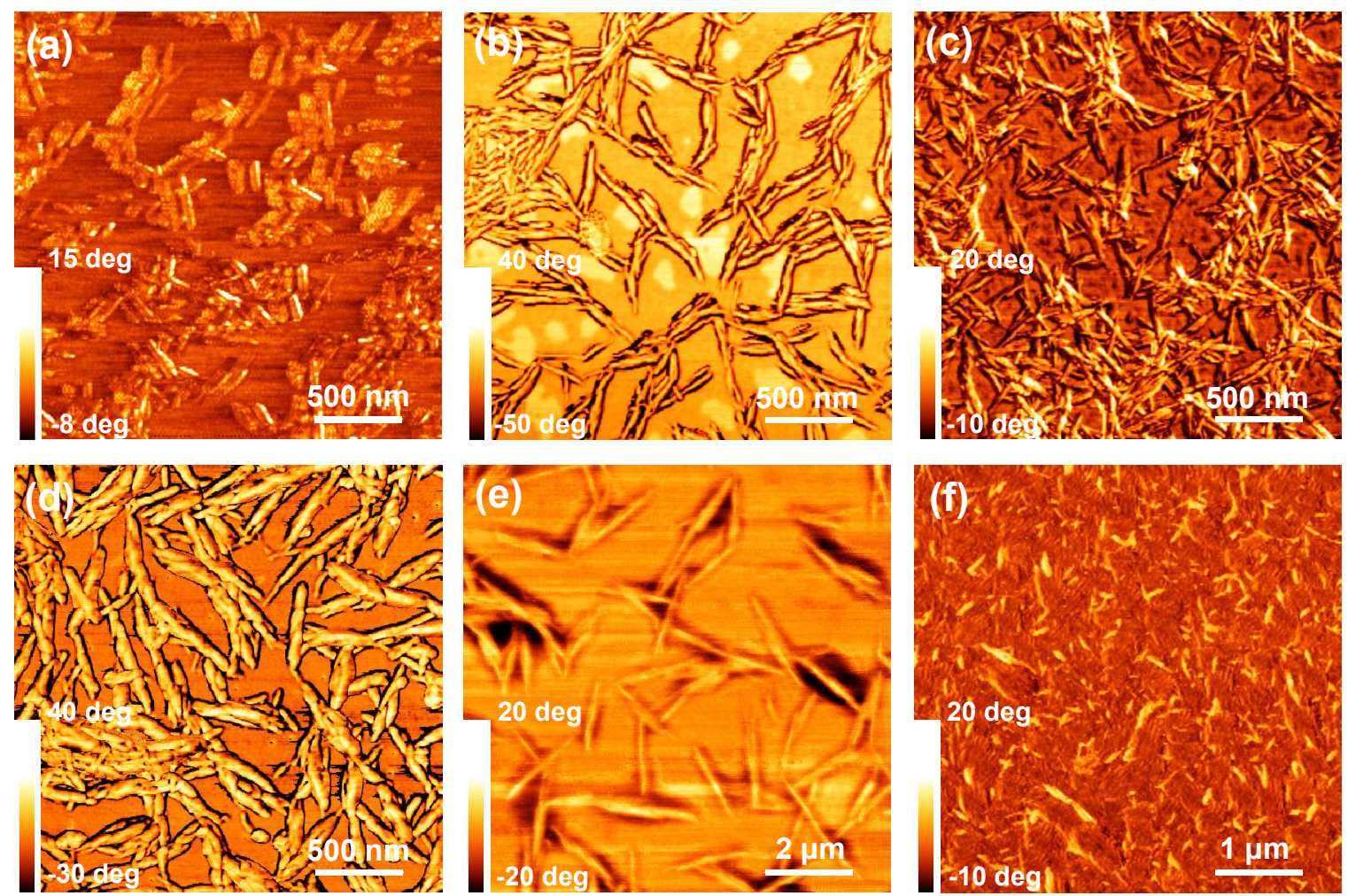

Figure S2. AFM phase images of (a) original unmodified CNCs; (b) mCNC2; (c) mCNC3-3; (d) mCNC4; (e) and (f) mCNC6. 

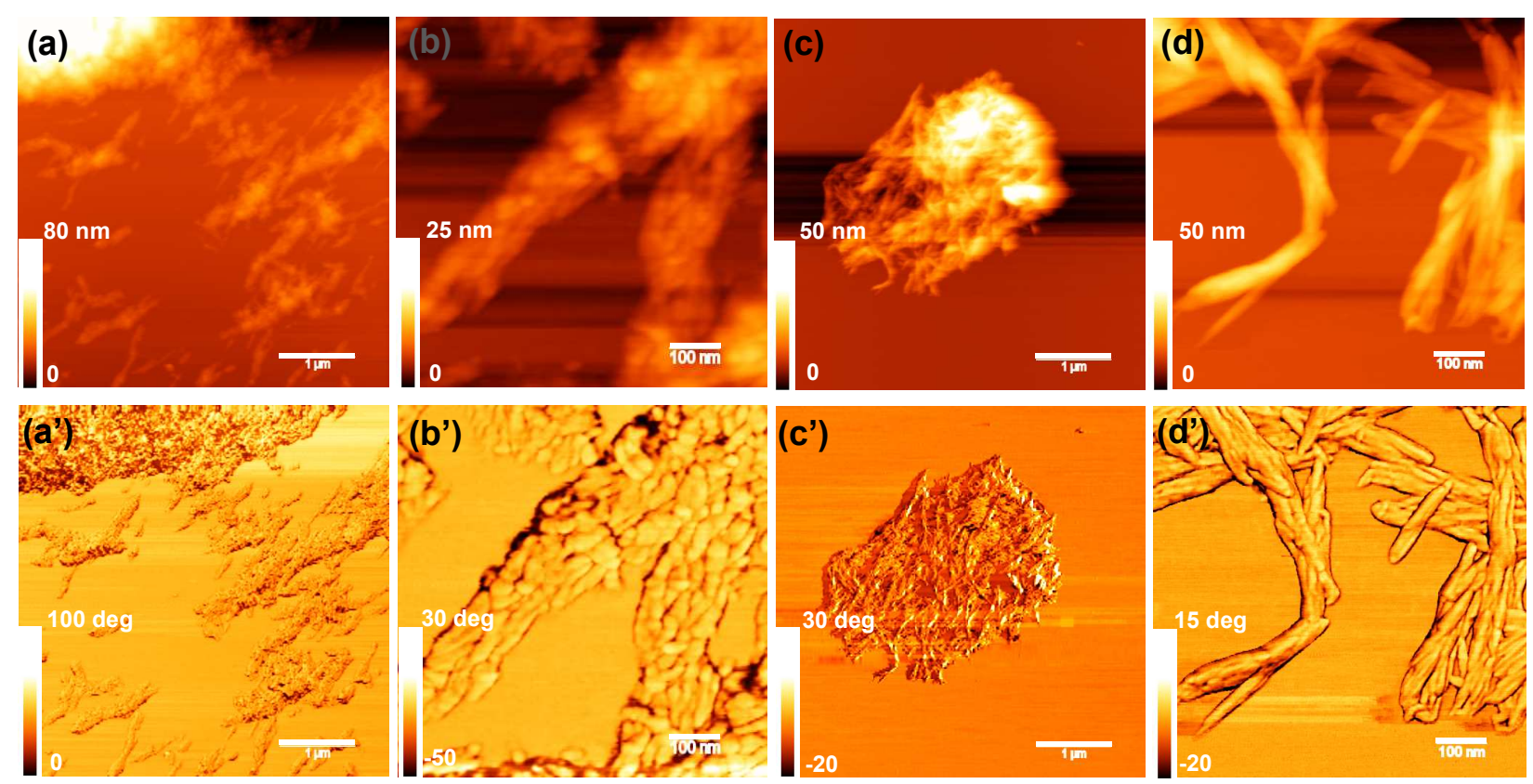

Figure S3. AFM height and phase images of aggregated CNC obtained in the control experiment by dropping CNC into pure THF (height images: a and b; phase images: a' and b'), CTAB-CNC dispersed in THF (height images: c and d; phase images: c' and d'). 

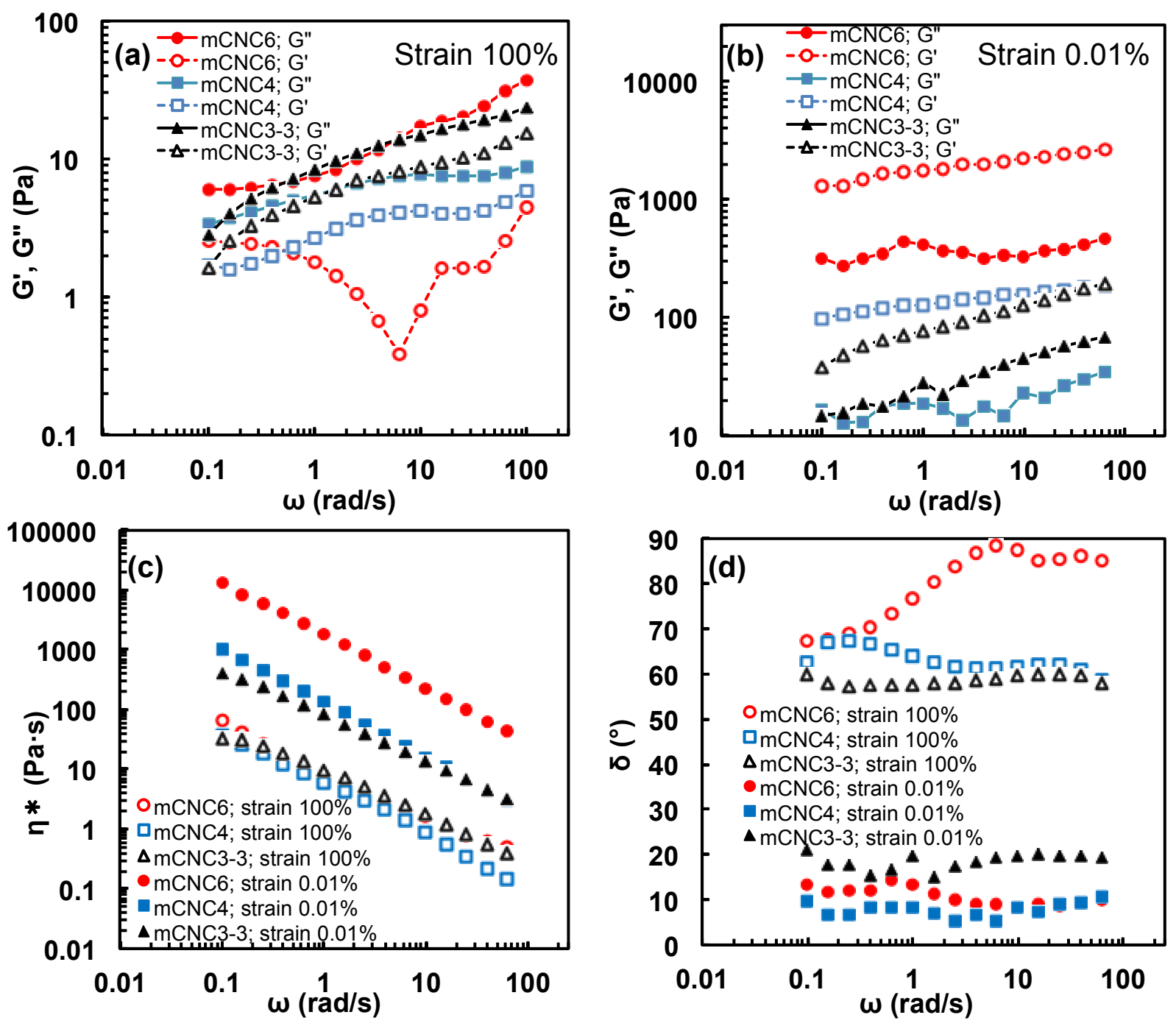

Figure S4. Rheological data from small amplitude dynamic oscillation measurements (at $10{ }^{\circ} \mathrm{C}$ ) of organo-gels of mCNC3-3, mCNC4, and mCNC6 in THF at the same concentration of $75 \mathrm{mg}$ $\mathrm{mL}^{-1}$ : (a) $\mathrm{G}^{\prime}$ and $\mathrm{G}^{\prime \prime}$ vs. $\omega$ at the strain of $100 \%$; (b) $\mathrm{G}^{\prime}$ and $\mathrm{G}^{\prime \prime}$ vs. $\omega$ at the strain of $0.01 \%$; (c) $\eta^{*}$ vs. $\omega$ at both strains of $100 \%$ and $0.01 \%$; (d) phase angle $(\delta)$ vs. $\omega$ at both strains. 


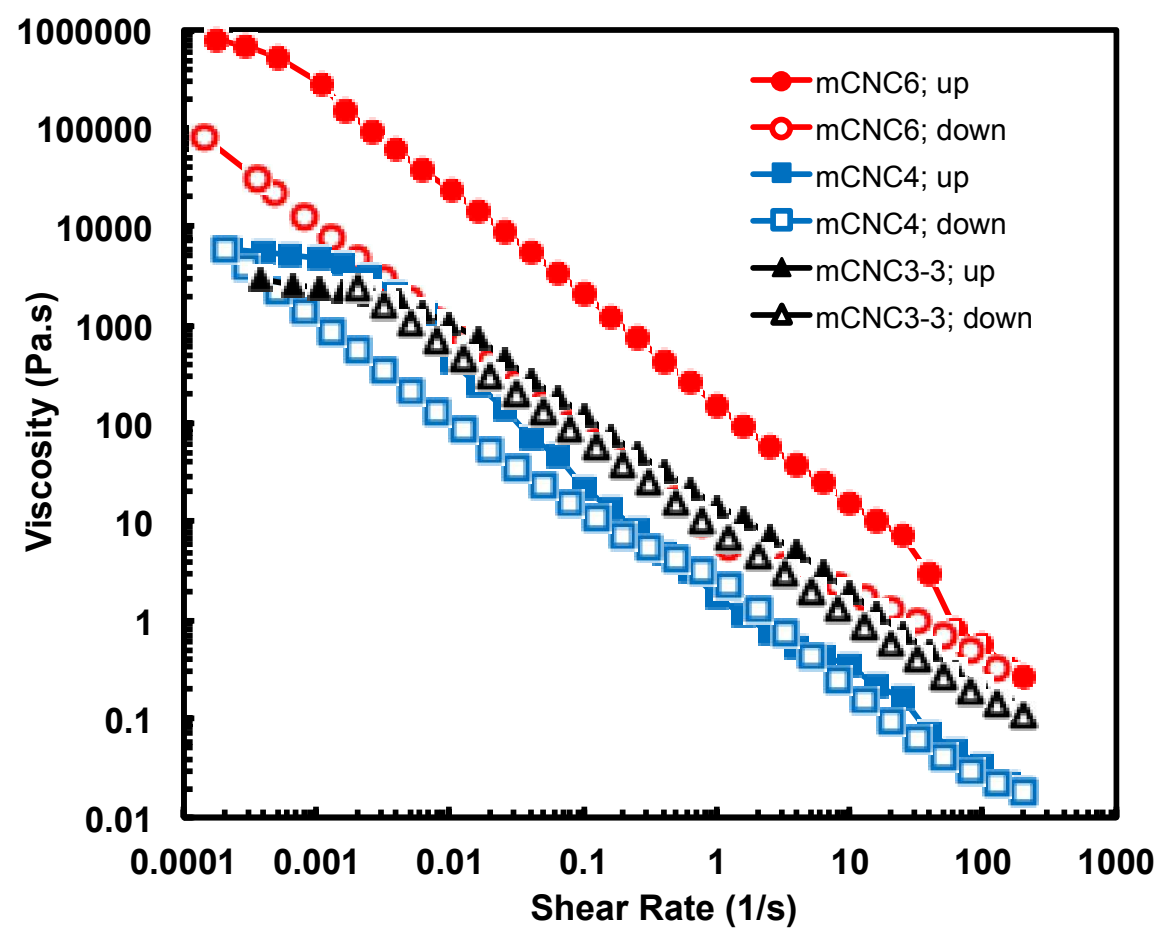

Figure S5. Viscosity vs. shear rate curves of organo-gels of mCNC3-3, mCNC4, and mCNC6 in THF at $75 \mathrm{mg} \mathrm{mL}^{-1}$ obtained through steady shear measurements at $10{ }^{\circ} \mathrm{C}$. 


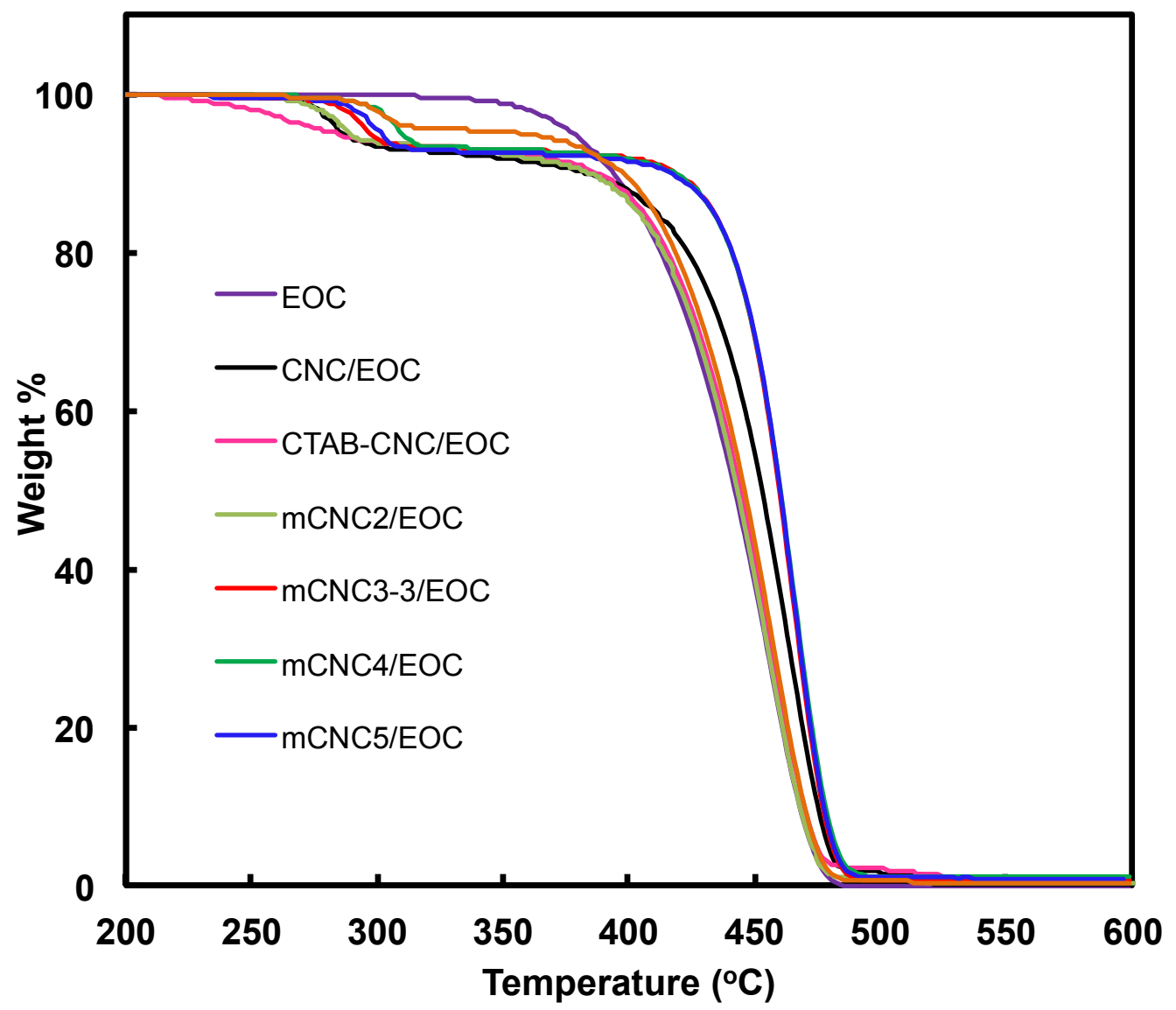

Figure S6. TGA curves of the various EOC composites and neat EOC. The measurements were undertaken at $10^{\circ} \mathrm{C} / \mathrm{min}$ in $\mathrm{N}_{2}$. 


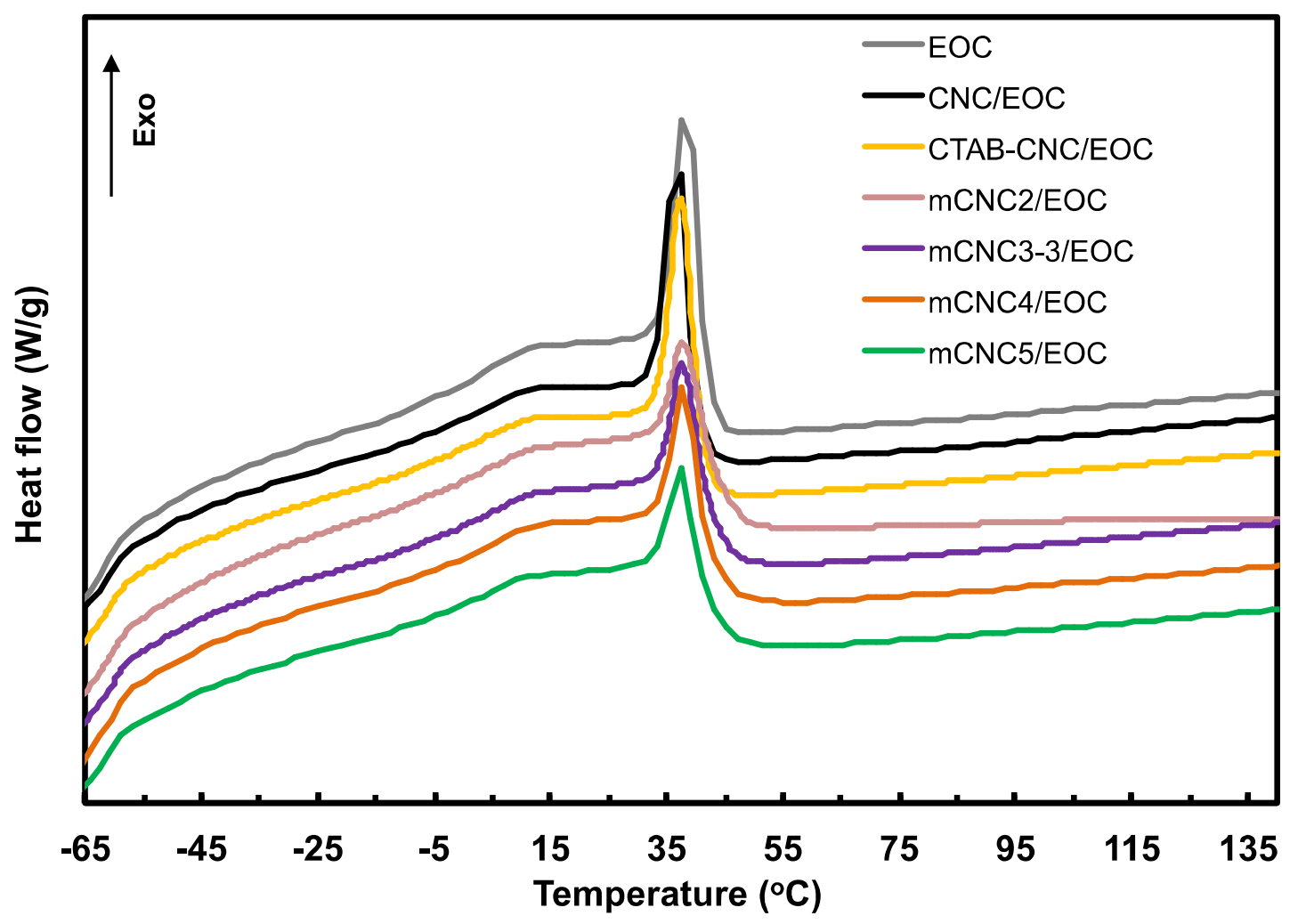

Figure S7. DSC crystallization curves of neat EOC and various EOC composites collected at cooling rate of $10^{\circ} \mathrm{C} / \mathrm{min}$. 